\title{
Abdominal Radiography
}

National Cancer Institute

\section{Source}

National Cancer Institute. Abdominal Radiography. NCI Thesaurus. Code C38102.

A radiographic procedure to form an image of the abdomen. 